\title{
Evolution of $\mathrm{Pd} / \mathrm{CeO}_{2}$ surface morphology in situ monitored by FTIR spectroscopy
}

\author{
A. Tereshchenko, A. Guda, V. Polyakov, Y. Rusalev, A.V. Soldatov \\ The Smart Materials Research Institute, Southern Federal University, 344090 Rostov-on-Don, Russia
}

tereshch1@gmail.com

Ceria supported nanoparticles (NPs) of noble metals are well-known catalysts for diverse hydrogenation and oxidation reactions [1,2]. Their catalytic activity depends on the dispersion and shape of NPs, support, functionalization, etc. However, the use of high Zsupport and small NPs limits their diagnostics especially in laboratory conditions [3]. In this study, we demonstrate a possibility of in situ monitoring the size and surface morphology of $\mathrm{Pd} / \mathrm{CeO}_{2}$ catalysts during the growth by using FTIR spectroscopy of adsorbed $\mathrm{CO}$.

Ceria NPs used as support were synthesized according to the method described in [4] and impregnated by $\mathrm{PdCl}_{2}$ [3]. Then, the material was put into the reaction chamber and heated in a flow of $\mathrm{Ar}$ up to 30,150 or $300{ }^{\circ} \mathrm{C}$ (samples Pd-30, Pd-150, Pd-300) for $30 \mathrm{~min}$. A mixture of $\mathrm{H}_{2}, \mathrm{CO}$ and $\operatorname{Ar}(2.5,1$ and $46.5 \mathrm{~mL} / \mathrm{min})$ was passed through the sample for 1 hour to reduce Pd NPs.

XRPD didn't allow distinguishing Pd NPs for all samples (Fig.1a). This fact could be explained by the small size of synthesized Pd NPs which caused broadening of peaks. Tests of catalytic (procedure described in [3]) shown that CO conversion was 25-70\% for all samples at $150{ }^{\circ} \mathrm{C}$ even without calcination (in case of $\mathrm{Pd}-150$ and $\mathrm{Pd}-300$ ) and decreased in row $\mathrm{Pd}-30>\mathrm{Pd}-150>\mathrm{Pd}-300$.
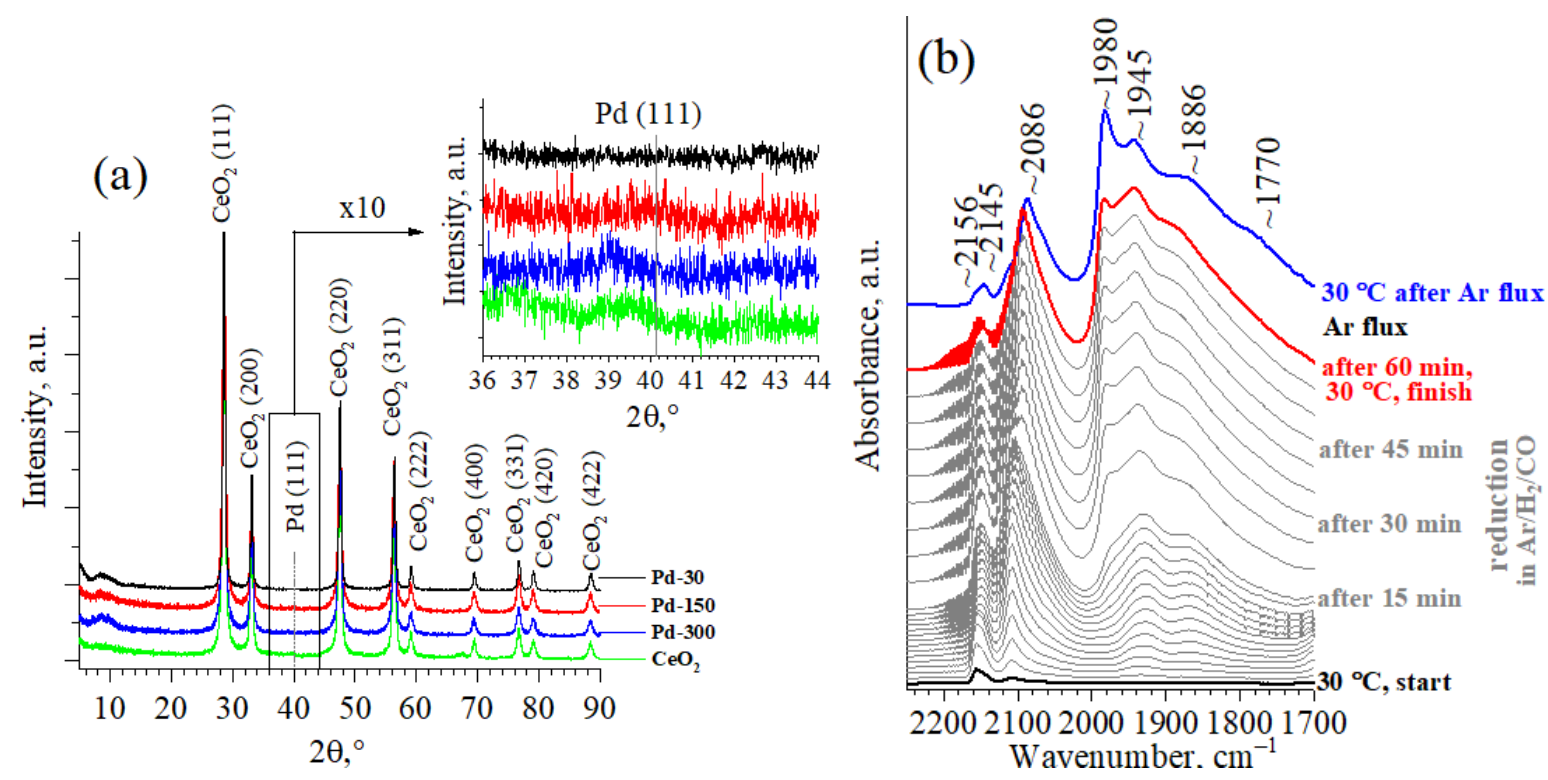

Figure 1. (a) XRPD patterns of all samples; (b) series of FTIR spectra during the synthesis of Pd-30.

The series of spectra collected in situ demonstrated that the reduction at high temperature (Pd-300 and Pd-150) was much faster than at low temperature (Pd-30). Also, it was observed that reduction was not complete for all samples: peaks of CO adsorbed on $\mathrm{Pd}^{2+}$ and $\mathrm{Pd}^{+}$ions were observed (ca. 2160 and $2110 \mathrm{~cm}^{-1}$ ). The last fact is explained by ceria support that prevented complete reduction. The process of reduction was observed in detail for the Pd-30 (Fig.1b) where the decrease of CO adsorbed on Pd ions was accompanied by the increase of peaks related to bridged carbonyls - evidence of appearing and growth of the extended surfaces. FTIR spectra allowed to determine the size of NPs which is proportional to the ratio of areas under peaks attributed to bridged (below $2000 \mathrm{~cm}^{-1}$ ) and linear $\left(2000-2100 \mathrm{~cm}^{-1}\right)$ carbonyls. Size decreased in row Pd-300 $>$ Pd-150 $>$ Pd-30. The dynamics of growth was clearly observed for Pd-30 and Pd-150 sample whereas for Pd-300 CO adsorbed only at 2- and 3-folded sites. Only carbonyls on $\mathrm{Pd}(111)$ faces were detected for Pd-150 and Pd-300 when both $\operatorname{Pd}(100)$ and $\operatorname{Pd}(111)$ facets were found for the Pd-30 sample.

While conventional techniques are limited by size of NPs (XRPD), poor contrast (TEM), require large scale facilities (XAS, SAXS), described laboratory technique allows determining the size and surface morphology in situ, at any desired moment of NPs growth. 
[1] Zang W., Li G., Wang L., Zhang X. (2015) Catal. Sci. Technol., 5, 2532-2553.

[2] Liang Q., Liu J., Wei Y., Zhao Z., MacLachlan M. J. (2013). Chem. Comm., 49, 8928-8930.

[3] Tereshchenko A., Polyakov V., Guda A., Lastovina T., Pimonova Y., Bulgakov A., et al. (2019). Catalysts, 9 , 385.

[4] Benmouhoub C., Kadri A., Benbrahim N., Hadji S. (2009). Materials Science Forum, 609, 189-194.

\section{Keywords: palladium; ceria; nanoparticles; CO probing molecules; FTIR; adsorption;}

The study was carried out with the financial support of the Russian Foundation for Basic Research (RFBR) in the framework of the scientific project №20-32-70227 